\title{
The relationships between asphalt ageing in lab and field based on the neural network
}

\section{Haitao Zhang, Xinxin Fu, Haiyang Jiang, Xiu Liu \& Lihua Lv}

To cite this article: Haitao Zhang, Xinxin Fu, Haiyang Jiang, Xiu Liu \& Lihua Lv (2015) The relationships between asphalt ageing in lab and field based on the neural network, Road Materials and Pavement Design, 16:2, 493-504, DOI: 10.1080/14680629.2015.1020846

To link to this article: http://dx.doi.org/10.1080/14680629.2015.1020846

\section{曲 Published online: 18 Mar 2015.}

\section{Submit your article to this journal $\llbracket$}

Џlll Article views: 100

Q View related articles $₫$

View Crossmark data $\asymp$ 


\title{
The relationships between asphalt ageing in lab and field based on the neural network
}

\author{
Haitao Zhang ${ }^{\mathrm{a} *}$, Xinxin $\mathrm{Fu}^{\mathrm{a}}$, Haiyang Jiang ${ }^{\mathrm{b}}$, Xiu Liu ${ }^{\mathrm{c}}$ and Lihua $\mathrm{Lv}^{\mathrm{a}}$ \\ ${ }^{a}$ College of Civil Engineering, Northeast Forestry University, Harbin, People's Republic of China; \\ ${ }^{b}$ Institute of Mechanics, Chinese Academy of Sciences, Beijing, People's Republic of China; ${ }^{\circ}$ School of \\ Transportation Science and Engineering, Harbin Institute of Technology, Harbin, People's Republic of \\ China
}

(Received 4 September 2014; accepted 15 February 2015)

\begin{abstract}
The lab ageing tests of $\mathrm{AH}-90$ asphalt (the $25^{\circ} \mathrm{C}$ penetration is about $80-100,0.1 \mathrm{~mm}$ ) have been done by the rotating thin film oven test and the ordinary convection oven under $163^{\circ} \mathrm{C}$ from 5 to $120 \mathrm{~h}$, and the macro-performance has been measured such as the penetration under $15^{\circ} \mathrm{C}, 25^{\circ} \mathrm{C}, 30^{\circ} \mathrm{C}$ and the ductility under $10^{\circ} \mathrm{C}$. Based on the back propagation neural network by MATLAB, the paper has trained the data of the asphalt penetration $\left(25^{\circ} \mathrm{C}\right)$ in the different service time of the asphalt pavement from the different zones in China, and predicted the $25^{\circ} \mathrm{C}$ penetration of the asphalt pavement ageing in the field at the different service time in cold zone. On the basis of it, the paper has established the relationships between the asphalt ageing simulated in the lab and the ageing in the field. The research conclusions have been put forward and suggested to apply in the recycled asphalt pavement.
\end{abstract}

Keywords: asphalt ageing; asphalt pavement; penetration; BP neural network; ageing rate

\section{Introduction}

The asphalt ageing is mainly classified into two stages, that is, the first stage for the short-term ageing (several hours), the second stage for the long-term ageing (several years). The asphalt ageing changes the asphalt macro-performance. The asphalt short-term ageing can be more easily determined in lab simulation, but asphalt long-term ageing will need several years. Its performance indexes cannot be determined timely. Therefore, the study of the relationship between the short-term ageing and the long-term ageing is of great significance.

The temperature of the asphalt short-term ageing simulated in the lab is about $163^{\circ} \mathrm{C}$, and the temperature of the asphalt long-term (actual) ageing of the asphalt pavement in the field is the asphalt pavement temperature less than $100^{\circ} \mathrm{C}$; therefore, there are different chemical reactions happening under different ageing temperatures. However, the chemical reactions during asphalt ageing mainly are oxidising reactions, and only the level or rate of the oxidising reactions is influenced by the different temperatures. According to the above point of view, the research is to discuss the asphalt ageing by using the methods of the macro-test and macroperformance and therefore, the oxidising reactions under different ageing temperatures will be reflected through the data of the macro-mechanical performance of ageing asphalt. It means that the differences between the different oxidising reactions can be evaluated through the data of

*Corresponding author. Email: zht6781@163.com 
the macro-mechanical performance. In fact, the asphalt ageing is influenced compositely by the multi-factors, such as temperature, air and pressure, and so on, and the related micro-research about the oxidising reactions of asphalt ageing will be researched at the next stage.

The macro-performance indexes of the asphalt short-term ageing can be evaluated by rotating thin film oven test (RTFOT) and the ordinary convection oven in the lab, but the data observation of the asphalt pavement ageing in different service time will take a long time to accumulate. Although Superpave has developed the PAV test to simulate the asphalt long-term ageing of about 5-10 years of the asphalt pavement, the predicting time of this method is limited (only 510 years) and indefinite, and the accuracy of the test data also needs to be further demonstrated. Therefore, the objective of the research is to develop a new method for predicting the asphalt long-term (actual) ageing by using the asphalt short-term lab ageing test data. This research project has established the relationships between the asphalt short-term ageing and the asphalt long-term (actual) ageing based on the back propagation (BP) neural network technology (Austroads, 1997; FHWA, 2001; Juristyarinia, Davisonb, \& Glover, 2011; Li, Zofkaa, Marasteanua, \& Clyne, 2006; Shenoy, 2002; Shoenberger \& DeMoss, 2005; Thomas, 2002; Xiao, Putmana, \& Amirkhanian, 2011; Zeiada, Kaloush, Underwood, \& Mamlouk, 2014).

\section{The tests of the asphalt ageing simulated in the lab}

\subsection{The tests of the asphalt ageing}

The AH-90 asphalt (the $25^{\circ} \mathrm{C}$ penetration is about $80-100,0.1 \mathrm{~mm}$ ) is applied as the specimens. The tests of the asphalt ageing have been done by using the RTFOT and the ordinary convection oven at $163^{\circ} \mathrm{C}$ and under ventilation condition, the ageing test time is $5,12,24,48,72,120 \mathrm{~h}$. The short-term ageing test is that the asphalt specimens are placed in RTFOT for $5 \mathrm{~h}$ at $163^{\circ} \mathrm{C}$, and the long-term ageing test is that the short-term ageing asphalt specimens after RTFOT are continuously placed in the convection oven for $120 \mathrm{~h}$ at $163^{\circ} \mathrm{C}$. The asphalt specimens in RTFOT are placed in the bottles, and the asphalt specimens in convection oven are placed in the pans.

The temperature range of RTFOT is $0-200^{\circ} \mathrm{C}$ and the temperature control is $163 \pm 0.5^{\circ} \mathrm{C}$, the airflow is $4000 \pm 200 \mathrm{ml} / \mathrm{min}$, the ageing time is $5 \pm 0.25 \mathrm{~h}$. The temperature range of the oven is $0-300^{\circ} \mathrm{C}$ and the temperature control is $163 \pm 1{ }^{\circ} \mathrm{C}$, the airflow is $4000 \pm 200 \mathrm{ml} / \mathrm{min}$, the ageing time is $120 \pm 0.5 \mathrm{~h}$.

Through the asphalt ageing tests, the macro-performance indexes of the ageing asphalt have been tested including the penetration $\left(15^{\circ} \mathrm{C}, 25^{\circ} \mathrm{C}, 30^{\circ} \mathrm{C}\right)$ and the ductility $\left(10^{\circ} \mathrm{C}\right)$, etc.

\subsection{The penetration and ductility of the ageing asphalt}

The test temperature of the penetration is $15^{\circ} \mathrm{C}, 25^{\circ} \mathrm{C}, 30^{\circ} \mathrm{C}$, and the test temperature of the ductility is $10^{\circ} \mathrm{C}$. The test results are shown in Table 1 and Figure 1.

The data results have indicated that the penetration of the ageing asphalt decreases with the ageing time increasing under the same temperature. The penetration decreases largely at

Table 1. The penetration and ductility results of the asphalt ageing.

\begin{tabular}{lrrrrrrrr}
\hline Time (h) & & 0 & 5 & 12 & 24 & 48 & 72 & 120 \\
\hline Penetration $(0.1 \mathrm{~mm})$ & $15^{\circ} \mathrm{C}$ & 32 & 25 & 15 & 14 & 12 & 11 & 10 \\
& $25^{\circ} \mathrm{C}$ & 78 & 61 & 53 & 41 & 31 & 17 & 11 \\
& $30^{\circ} \mathrm{C}$ & 144 & 100 & 83 & 69 & 56 & 28 & 18 \\
Ductility $(\mathrm{cm})$ & $10^{\circ} \mathrm{C}$ & 46 & 40 & 25.5 & 12.9 & 11.6 & 1.1 & 0.8 \\
\hline
\end{tabular}



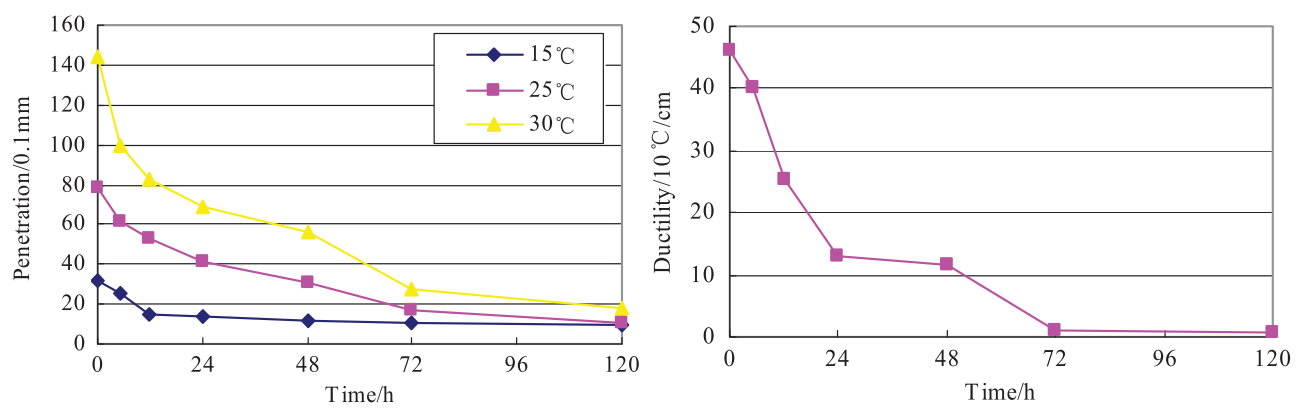

Figure 1. The penetration and ductility curve of the asphalt ageing.

the beginning and gradually decreases slowly, and the indexes of the penetration in different temperature have approached gradually with the ageing time increases. From the test data, the ductility of the ageing asphalt also decreases with the ageing time increasing, and the change is from fast to slow. The ageing asphalt is very crisp and not of the elasticity after $72 \mathrm{~h}$ (Ministry of Communication, 2004, 2006, 2008, 2011).

\section{The data investigation and prediction of the asphalt pavement ageing}

\subsection{The data investigation and process of the asphalt pavement ageing}

It will take a long time to accumulate the data of the asphalt pavement ageing in the field. The research has surveyed and collected the data of the asphalt pavement ageing of different service times at different zones in China.

After the data process, the data of the asphalt pavement ageing in the field at the different service time in different zones are shown in Table 2.

\subsection{The data prediction of the asphalt pavement ageing (Parvini, 2002; Shi, 2010; Yuan, 1999)}

\subsubsection{The principles of the BP neural network}

The BP neural network is a mathematics model to imitate the bio-neural network behaviour features for the information processing. It is composed by the large neural elements through their mutual connection, the general structure includes the input layer, the implied layer and the output layer. Each neural element is a special function called "activation function", and the connection value between two neural elements characterises the mutual strength called "right value". The network output depends on the connecting way of the neural elements, the incentive function and the corresponding right value.

The BP neural network is a multilayer feed-forward neural network, and can be applied in the nonlinear systems instead of the mathematics modelling. It includes two parts, that is, the input and output data system and the predicting system; it can express the unknown function by the training network using input and output data, and the network predicting system can be output. Its structure is shown in Figure 2, where $X_{1}, X_{2} \ldots X_{n}$ is the input value of the neural network, $Y_{1}, Y_{2} \ldots Y_{m}$ is the output value (predicting value), $\omega_{i j}$ and $\omega_{j k}$ are the right values, the neural elements of the input layer, the hidden layer and the output layer are $n, l, m$, that is, the network structure is $n-l-m$. 
Table 2. The penetration and ratio of remaining penetration of the asphalt pavement ageing.

\begin{tabular}{|c|c|c|c|c|c|c|c|c|c|c|}
\hline \multirow[b]{2}{*}{ Service time (y) } & \multicolumn{10}{|c|}{ Zones } \\
\hline & 1 & 2 & 3 & 4 & 5 & 1 & 2 & 3 & 4 & 5 \\
\hline & \multicolumn{5}{|c|}{ Penetration $\left(25^{\circ} \mathrm{C}, 0.1 \mathrm{~mm}\right)$} & \multicolumn{5}{|c|}{ Ratio of remaining penetration $\left(25^{\circ} \mathrm{C}\right)$} \\
\hline 0 & 91 & 68 & 128 & 80 & 86 & 1 & 1 & 1 & 1 & 1 \\
\hline 2 & 54 & 41 & 82 & 57 & 59 & 0.593 & 0.603 & 0.641 & 0.713 & 0.686 \\
\hline 3 & 48 & & & & & 0.527 & & & & \\
\hline 6 & 35 & & & & & 0.385 & & & & \\
\hline 7 & 29 & 30 & 85 & 53 & 53 & 0.319 & 0.441 & 0.664 & 0.663 & 0.616 \\
\hline 8 & & & & 41 & & & & & 0.513 & \\
\hline 9 & & 23 & 55 & & 30 & & 0.338 & 0.430 & & 0.349 \\
\hline 10 & 32 & & 54 & 48 & & 0.352 & & 0.422 & 0.600 & \\
\hline 11 & & & & & 24 & & & & & 0.279 \\
\hline 12 & & 20 & & 41 & 20 & & 0.294 & & 0.513 & 0.233 \\
\hline 13 & & & 57 & & & & & 0.445 & & \\
\hline 14 & 30 & 19 & 56 & 40 & 22 & 0.330 & 0.279 & 0.437 & 0.500 & 0.256 \\
\hline
\end{tabular}

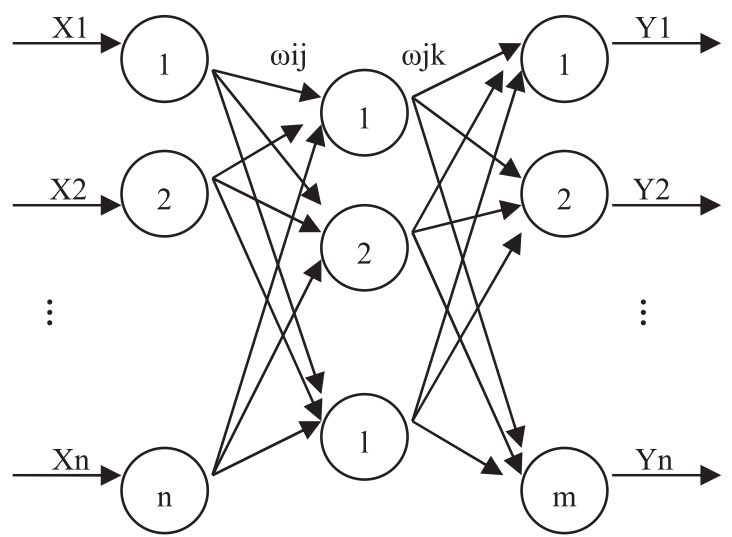

Figure 2. The structure of the BP neural network by MATLAB.

The calculation procedure of the BP neural network is shown in Figure 3. The training process of the BP neural network by MATLAB is as follows:

(1) The network initial

The input and the output data $(X, Y)$ determine the network input layer node number $n$, the hidden layer node number is $l$, the output layer node number is $m$. Through the neural element incentive function, the initials of the right value are $\omega_{i j}$ and $\omega_{j k}$, the initials of the implied layer and the output layer valve are $a$ and $b$.

(2) The hidden layer output $H$ is calculated as

$$
H_{j}=f\left(\sum_{i=1}^{n} \omega_{i j} x_{i}-a_{j}\right), \quad j=1,2, \ldots, l,
$$

where $f$ is The hidden layer activation function, $n$ is the input node number, and $l$ is the hidden layer node number. 


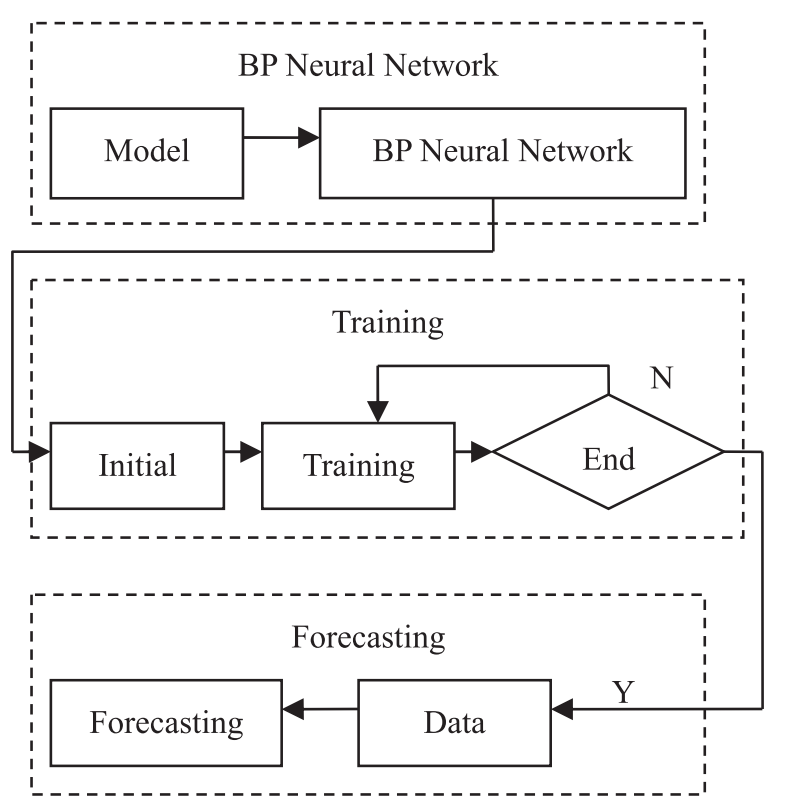

Figure 3. The calculation procedure of the BP neural network.

(3) The output layer output $H$ is calculated as

$$
O_{k}=\sum_{j=1}^{l} H_{j} \omega_{j k}-b_{k}, \quad k=1,2, \ldots, m,
$$

where $m$ is the output node number.

(4) The network predicting error $e$ is calculated as

$$
e_{k}=Y_{k}-O_{k}, \quad k=1,2, \ldots, m,
$$

where $Y$ is the expected output and $O$ is the predicting output.

(5) The update of the right value $\omega_{i j}$ and $\omega_{j k}$ in the network connection

$$
\begin{aligned}
& \omega_{i j}=\omega_{i j}+\eta H_{j}\left(1-H_{j}\right) x_{(i)} \sum_{k=1}^{m} \omega_{j k} e_{k}, \quad i=1,2, \ldots, n, j=1,2, \ldots, l, \\
& \omega_{j k}=\omega_{j k}+\eta H_{j} e_{k}, \quad j=1,2, \ldots, l, k=1,2, \ldots, m,
\end{aligned}
$$

where $\eta$ is learn rate.

(6) The update of the $a, b$

$$
\begin{aligned}
& a_{j}=a_{j}+\eta H_{j}\left(1-H_{j}\right) \sum_{k=1}^{m} \omega_{j k} e_{k}, \quad j=1,2, \ldots, l, \\
& b_{k}=b_{k}+e_{k}, \quad k=1,2, \ldots, m .
\end{aligned}
$$

(7) The algorithm iteration decision

If no end, back to (2). 
Table 3. The climatic data at different zones in China (1960-2000).

\begin{tabular}{lcccc}
\hline & \multicolumn{2}{l}{ Temperature $\left({ }^{\circ} \mathrm{C}\right)$} & & \\
\cline { 2 - 3 } Zones & Max. & Min. & Freezing Index $\left({ }^{\circ} \mathrm{C} / \mathrm{d}\right)$ & Precipitation $(\mathrm{mm} / \mathrm{y})$ \\
\hline 1 & 36 & -11 & 46 & 613.8 \\
2 & 35 & 3 & 0 & 1701.3 \\
3 & 31 & -27 & 882 & 683.8 \\
4 & 34 & -27 & 1082 & 326.9 \\
5 & 35 & -10 & 15 & 1153.7 \\
Harbin & 31 & -34 & 1623 & 494.7 \\
\hline
\end{tabular}

Note: The data of the temperature in column 2 are the average of the data from 1960 to 2000.

\subsubsection{The data training and establishment of the BP neural network by MATLAB}

The MATLAB software takes the matrix as the basic unit of the data processing. The MATLAB neural network toolbox based on the neural network theory constructs several parts together by using MATLAB language; these parts include a variety of the neural network, the typical activation function and the learning rules out. The BP neural network in this paper is realised based on the MATLAB neural network toolbox.

3.2.2.1. The data training. (1) The data input: The data of the asphalt pavement actual ageing were collected from five different zones in China (Table 2), and the data of the asphalt pavement actual ageing in Harbin have been predicted by using BP neural network. The influencing factors to the asphalt ageing mainly include the temperature, light, air, and so on. The input data include the road service time, the highest temperature, the lowest temperature, the annual freezing index and the precipitation. The related climatic data have been collected and shown in Table 3.

(2) The data output: The output data are the ratio of $25^{\circ} \mathrm{C}$ remaining penetration of the asphalt pavement ageing.

(3) The data normalisation: For the network predicting errors, the data of the input and output have been transferred into $[0,1]$, that is, data normalisation. The function of the MATLAB data normalisation is determined as $x_{k}=\left(x_{k}-x_{\min } / x_{\max } .-x_{\min }\right.$. $)$ by using the max.-min. method, $x_{\max }$ and $x_{\min }$. are the maximum value and the minimum value in the sequence.

3.2.2.2. The establishment of the BP neural network by MATLAB. Through the input and output data, the input and output layer node numbers of the neural network are respectively determined as 5 and 1 . The hidden layer number and node number are determined by the training effects. The transferring function of the hidden layer and output layer node is respectively determined as the tangent $\mathrm{S}$ type function "tansig" and the linear function "purelin". The training function is "trainlm" and the network learning function is "learngdm".

In network training, the number of iterations is 100 , the learning rate is 0.1 , the target of the training error is 0.00004 , and these data are stored in the file of data.mat. The input is for the training input data, and the output is for the training output data, the inputpre is for the predicting input data. The training group of the input and output data is 18 .

For the training effects, the mean square error (MSE) and mean relative error (MRE) are applied in the network training; the related functions are as follows:

$$
\mathrm{MSE}=\frac{\sum_{i=1}^{n}\left(y_{i}-y_{i}^{\prime}\right)^{2}}{n}, \quad \mathrm{MRE}=\frac{\sum_{i=1}^{n}\left|y_{i}-y_{i}^{\prime}\right| / y_{i}}{n}
$$


Table 4. The training data results.

\begin{tabular}{|c|c|c|c|c|c|}
\hline \multicolumn{5}{|l|}{ Input training data } & \multirow{3}{*}{$\begin{array}{l}\text { Output training data } \\
\text { Ratio of remaining } \\
\text { penetration }\left(25^{\circ} \mathrm{C}\right)\end{array}$} \\
\hline \multirow[b]{2}{*}{ Service time (y) } & \multicolumn{2}{|c|}{ Temperature $\left({ }^{\circ} \mathrm{C}\right)$} & \multirow{2}{*}{$\begin{array}{c}\text { Freezing } \\
\text { Index }\left({ }^{\circ} \mathrm{C} / \mathrm{d}\right)\end{array}$} & \multirow{2}{*}{$\begin{array}{c}\text { Precipitation } \\
(\mathrm{mm} / \mathrm{y})\end{array}$} & \\
\hline & Max. & Min. & & & \\
\hline 2 & 57.5 & -11 & 46 & 613.8 & 0.593 \\
\hline 3 & 57.5 & -11 & 46 & 613.8 & 0.527 \\
\hline 6 & 57.5 & -11 & 46 & 613.8 & 0.385 \\
\hline 10 & 57.5 & -11 & 46 & 613.8 & 0.352 \\
\hline 14 & 57.5 & -11 & 46 & 613.8 & 0.330 \\
\hline 9 & 57.8 & 3 & 0 & 1701.3 & 0.338 \\
\hline 12 & 57.8 & 3 & 0 & 1701.3 & 0.294 \\
\hline 2 & 50.9 & -27 & 882 & 683.8 & 0.641 \\
\hline 9 & 50.9 & -27 & 882 & 683.8 & 0.430 \\
\hline 10 & 50.9 & -27 & 882 & 683.8 & 0.422 \\
\hline 2 & 53.2 & -27 & 1082 & 326.9 & 0.713 \\
\hline 7 & 53.2 & -27 & 1082 & 326.9 & 0.663 \\
\hline 10 & 53.2 & -27 & 1082 & 326.9 & 0.600 \\
\hline 12 & 53.2 & -27 & 1082 & 326.9 & 0.513 \\
\hline 7 & 56.9 & -10 & 15 & 1153.7 & 0.616 \\
\hline 9 & 56.9 & -10 & 15 & 1153.7 & 0.349 \\
\hline 11 & 56.9 & -10 & 15 & 1153.7 & 0.279 \\
\hline 12 & 56.9 & -10 & 15 & 1153.7 & 0.233 \\
\hline
\end{tabular}

Note: The temperature in column 2 is the pavement surface temperature calculated by climatic temperature.

where $n$ is the number of the training data, $y$ is the expected output data, and $y^{\prime}$ is the predicting output data.

According to the actual training effects and comparisons, the two hidden layer and eight nodes are determined. Therefore, the structure of the BP neural network by MATLAB is 5-8 and 8-1.

\subsubsection{The results of the training and predicting data}

3.2.3.1. The training data results. The input training data include the service time, the highest and lowest temperature, the freezing index and the precipitation, the output training data are the ratio of remaining penetration of the asphalt pavement ageing. The training data results are shown in Table 4.

3.2.3.2. The predicting input data results. The predicting input data include the road service time and four climatic data in Harbin, the meaning of four climatic data is the same as Table 4. The four climatic data in different service time have not changed because these climatic data are obtained by the investigation from 1960 to 2000. The predicting input data results are shown in Table 5.

3.2.3.3. The predicting output data results. In the different predicting output data results, according to the MSE and MRE with the actual data, the research has selected the data of $r_{1}$ and $r_{2}$ as the predicting results of the asphalt pavement actual ageing in Harbin, $r_{1}$ is fit to the prediction for the short service time and $r_{2}$ is fit to the prediction for the long service time. The training effects are shown in Figure 4. 
Table 5. The predicting input data results.

\begin{tabular}{|c|c|c|c|c|}
\hline \multicolumn{5}{|c|}{ Predicting input data } \\
\hline \multirow[b]{2}{*}{ Service time (y) } & \multicolumn{2}{|c|}{ Temperature $\left({ }^{\circ} \mathrm{C}\right)$} & \multirow[b]{2}{*}{ Freezing Index $\left({ }^{\circ} \mathrm{C} / \mathrm{d}\right)$} & \multirow[b]{2}{*}{ Precipitation $(\mathrm{mm} / \mathrm{y})$} \\
\hline & Max. & Min. & & \\
\hline 1 & 49.7 & -34 & 1623 & 494.7 \\
\hline 2 & 49.7 & -34 & 1623 & 494.7 \\
\hline 3 & 49.7 & -34 & 1623 & 494.7 \\
\hline 4 & 49.7 & -34 & 1623 & 494.7 \\
\hline 5 & 49.7 & -34 & 1623 & 494.7 \\
\hline 6 & 49.7 & -34 & 1623 & 494.7 \\
\hline 7 & 49.7 & -34 & 1623 & 494.7 \\
\hline 8 & 49.7 & -34 & 1623 & 494.7 \\
\hline 9 & 49.7 & -34 & 1623 & 494.7 \\
\hline 10 & 49.7 & -34 & 1623 & 494.7 \\
\hline 11 & 49.7 & -34 & 1623 & 494.7 \\
\hline 12 & 49.7 & -34 & 1623 & 494.7 \\
\hline 13 & 49.7 & -34 & 1623 & 494.7 \\
\hline 14 & 49.7 & -34 & 1623 & 494.7 \\
\hline 15 & 49.7 & -34 & 1623 & 494.7 \\
\hline
\end{tabular}

Note: The temperature in column 2 is the pavement surface temperature calculated by the climatic temperature in Harbin.
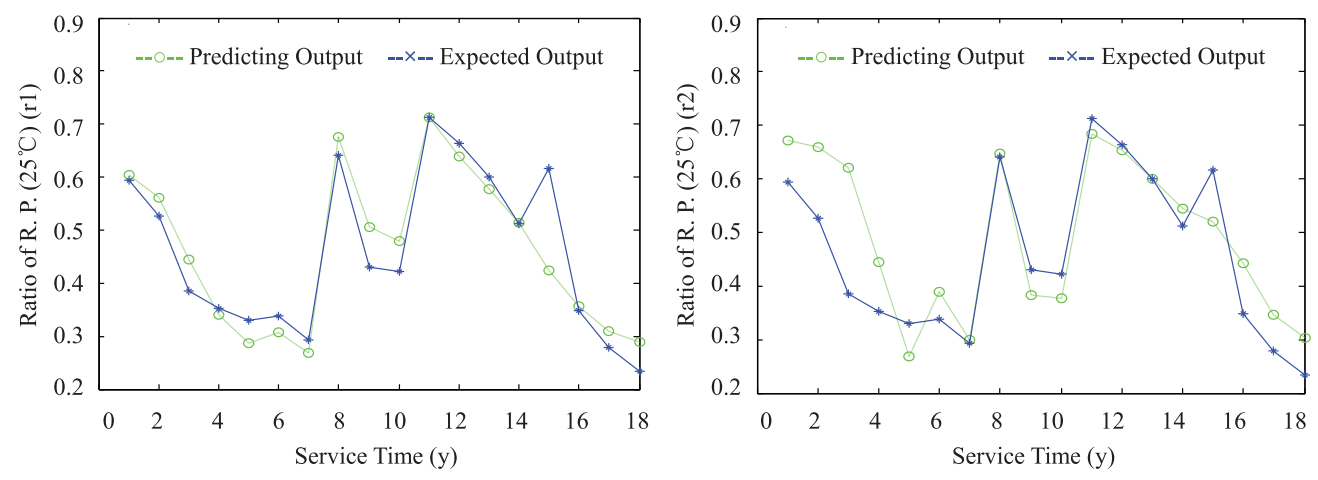

Figure 4. The network predicting and expected output $\left(r_{1}\right.$ and $\left.r_{2}\right)$.

It can be seen from Figure 4, the predicting output data is very close to the expected output data; therefore, the predicting output data in Figure 4 can be used as the actual predicting data for the asphalt pavement ageing in Harbin. The predicting output data results are shown in Table 6.

\section{The relationships between the asphalt ageing simulated in the lab and in the field}

\subsection{The ageing time relationships (Gandhia, Akisettya, \& Amirkhanian, 2009; Hajja, Sebaalya, \& Shrestha, 2009; Hong, Guo, \& Zhou, 2014)}

Through the analysis on the data of the asphalt ageing in the lab and in field, the time relationships between the asphalt ageing simulated in the lab and in the field based on the penetration are shown in Table 7 and Figure 5.

Table 7 and Figure 5 have indicated that the time relationship between lab and field for $r_{1}$ is fit to the early service time of asphalt pavement ageing in Harbin and $r_{2}$ is fit to the later service 
Table 6. The predicting output data results $\left(r_{1}\right.$ and $\left.r_{2}\right)$.

\begin{tabular}{|c|c|c|c|c|c|c|c|c|c|}
\hline \multirow[b]{2}{*}{$\begin{array}{l}\text { Service } \\
\text { Time }(y)\end{array}$} & \multicolumn{2}{|c|}{$r_{1}$} & \multicolumn{2}{|c|}{$r_{2}$} & \multirow[b]{2}{*}{$\begin{array}{l}\text { Service } \\
\text { Time }(y)\end{array}$} & \multicolumn{2}{|c|}{$r_{1}$} & \multicolumn{2}{|c|}{$r_{2}$} \\
\hline & $\begin{array}{l}\text { Ratio of } \\
\text { remaining } \\
\text { penetration } \\
\left(25^{\circ} \mathrm{C}\right)\end{array}$ & $\begin{array}{c}\text { Penetration } \\
\left(25^{\circ} \mathrm{C}, 0.1 \mathrm{~mm}\right)\end{array}$ & $\begin{array}{l}\text { Ratio of } \\
\text { remaining } \\
\text { penetration } \\
\left(25^{\circ} \mathrm{C}\right)\end{array}$ & $\begin{array}{c}\text { Penetration } \\
\left(25^{\circ} \mathrm{C}, 0.1 \mathrm{~mm}\right)\end{array}$ & & $\begin{array}{l}\text { Ratio of } \\
\text { remaining } \\
\text { penetration } \\
\left(25^{\circ} \mathrm{C}\right)\end{array}$ & $\begin{array}{c}\text { Penetration } \\
\left(25^{\circ} \mathrm{C}, 0.1 \mathrm{~mm}\right)\end{array}$ & $\begin{array}{l}\text { Ratio of } \\
\text { remaining } \\
\text { penetration } \\
\left(25^{\circ} \mathrm{C}\right)\end{array}$ & $\begin{array}{c}\text { Penetration } \\
\left(25^{\circ} \mathrm{C}, 0.1 \mathrm{~mm}\right)\end{array}$ \\
\hline 0 & 1 & 78 & 1 & 78 & 8 & 0.57 & 44.12 & 0.32 & 24.90 \\
\hline 1 & 0.69 & 53.57 & 0.54 & 42.47 & 9 & 0.55 & 42.62 & 0.31 & 23.96 \\
\hline 2 & 0.68 & 53.04 & 0.48 & 37.72 & 10 & 0.53 & 41.50 & 0.30 & 23.15 \\
\hline 3 & 0.67 & 52.04 & 0.44 & 33.98 & 11 & 0.52 & 40.77 & 0.29 & 22.47 \\
\hline 4 & 0.65 & 50.60 & 0.40 & 31.15 & 12 & 0.52 & 40.31 & 0.28 & 21.94 \\
\hline 5 & 0.63 & 48.94 & 0.37 & 29.01 & 13 & 0.51 & 40.01 & 0.28 & 21.60 \\
\hline 6 & 0.61 & 47.33 & 0.35 & 27.35 & 14 & 0.51 & 39.78 & 0.28 & 21.49 \\
\hline 7 & 0.59 & 45.76 & 0.33 & 26.02 & 15 & 0.51 & 39.55 & 0.28 & 21.63 \\
\hline
\end{tabular}

Note: $r_{1}: \mathrm{MSE}=0.0298, \mathrm{MRE}=0.0797 ; r_{2}: \mathrm{MSE}=0.1740, \mathrm{MRE}=0.1169$. 
Table 7. The time of the asphalt ageing simulated in the lab and in the field $\left(r_{1}\right.$ and $\left.r_{2}\right)$.

\begin{tabular}{|c|c|c|c|c|c|c|c|c|c|}
\hline \multirow[b]{2}{*}{$\begin{array}{c}\text { Penetration } \\
\left(25^{\circ} \mathrm{C}, 0.1\right. \\
\mathrm{mm})\end{array}$} & \multicolumn{2}{|c|}{$r_{1}$} & \multicolumn{2}{|c|}{$r_{2}$} & \multirow[b]{2}{*}{$\begin{array}{l}\text { Penetration } \\
\left(25^{\circ} \mathrm{C}, 0.1\right. \\
\mathrm{mm})\end{array}$} & \multicolumn{2}{|c|}{$r_{1}$} & \multicolumn{2}{|c|}{$r_{2}$} \\
\hline & $\begin{array}{l}\text { Lab } \\
\text { time } \\
\text { (h) }\end{array}$ & $\begin{array}{c}\text { Field } \\
\text { time } \\
\text { (y) }\end{array}$ & $\begin{array}{l}\text { Lab time } \\
\text { (h) }\end{array}$ & $\begin{array}{l}\text { Field } \\
\text { time (y) }\end{array}$ & & $\begin{array}{l}\text { Lab time } \\
\text { (h) }\end{array}$ & $\begin{array}{c}\text { Field } \\
\text { time (y) }\end{array}$ & $\begin{array}{l}\text { Lab time } \\
\text { (h) }\end{array}$ & $\begin{array}{l}\text { Field } \\
\text { time (y) }\end{array}$ \\
\hline 78 & 0 & 0 & 0 & 0 & 45 & 19 & 7.5 & & \\
\hline 75 & 0.9 & 0.1 & & & 43 & & & 22 & 1 \\
\hline 70 & 2 & 0.2 & 2 & 0.1 & 42 & 22.5 & 9.5 & & \\
\hline 65 & 3.3 & 0.5 & & & 41 & 23 & 10 & & \\
\hline 60 & 5.2 & 0.7 & 5.2 & 0.5 & 40 & 25.8 & 13 & 25.5 & 1.3 \\
\hline 55 & 9.8 & 0.9 & & & 34 & & & 41 & 3 \\
\hline 53 & 12 & 2 & & & 31 & & & 48 & 4 \\
\hline 52 & 13 & 3 & & & 29 & & & 52 & 5 \\
\hline 51 & 14.5 & 4 & & & 26 & & & 56 & 7 \\
\hline 50 & & & 14.5 & 0.9 & 24 & & & 60 & 9 \\
\hline 49 & 15.5 & 5 & & & 22 & & & 64 & 12 \\
\hline
\end{tabular}
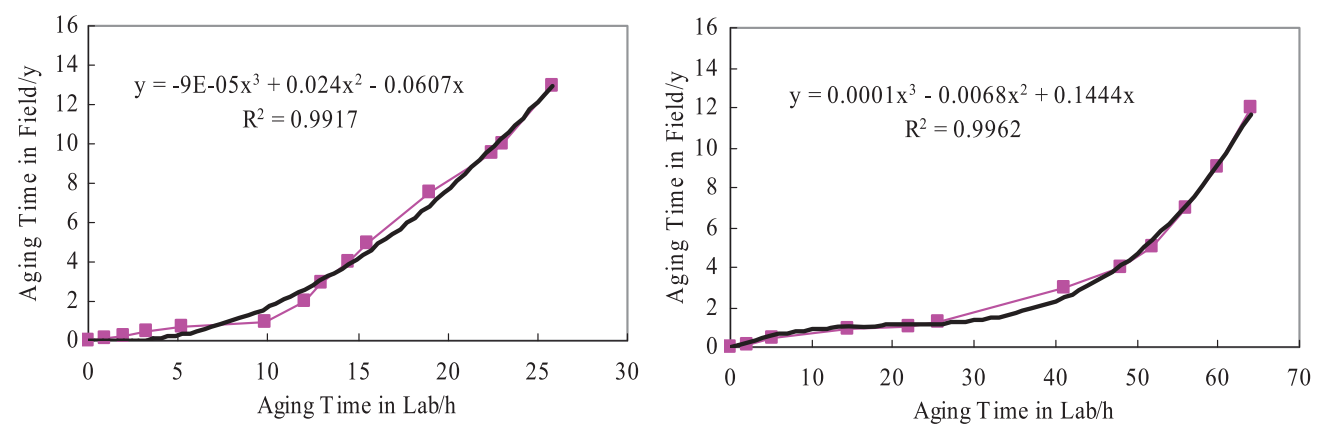

Figure 5. The time relationship between the asphalt ageing simulated in the lab and in the field $\left(r_{1}\right.$ and $\left.r_{2}\right)$.

Table 8. The calculation results of the rate of the asphalt ageing simulated in the lab.

\begin{tabular}{lccc}
\hline Time $(\mathrm{h})$ & Lab rate $(0.1 \mathrm{~mm} / 10 \mathrm{~h})$ & Time $(\mathrm{h})$ & Lab rate $(0.1 \mathrm{~mm} / 10 \mathrm{~h})$ \\
\hline 10 & 2.4 & 70 & 0.5 \\
20 & 1.0 & 80 & 0.3 \\
30 & 0.6 & 90 & 0.2 \\
40 & 0.4 & 100 & 0.1 \\
50 & 0.4 & 110 & 0.1 \\
60 & 0.5 & 120 & 0.1 \\
\hline
\end{tabular}

time of asphalt pavement ageing. This result has been proved through the comparisons between the test data and actual data.

\subsection{The ageing rate relationships}

The ageing rate is defined as the change in value of the asphalt penetration before and after the ageing per unit of time ( $10 \mathrm{~h}$ for lab time, 1 year for the field time). The calculation results of the average rate are shown in Tables 8 and 9 and Figure 6. 
Table 9. The calculation results of the rate of the asphalt ageing in the field.

\begin{tabular}{lcccccc}
\hline & \multicolumn{2}{c}{ Field rate $(0.1 \mathrm{~mm} / \mathrm{y})$} & & \multicolumn{2}{c}{ Field rate $(0.1 \mathrm{~mm} / \mathrm{y})$} \\
\cline { 2 - 3 } Time $(\mathrm{y})$ & \multicolumn{1}{c}{$r_{1}$} & $r_{2}$ & & Time $(\mathrm{y})$ & $r_{1}$ & $r_{2}$ \\
\hline 1 & 24.43 & 35.53 & 8 & 1.63 & 1.11 \\
2 & 0.53 & 4.75 & 9 & 1.50 & 0.95 \\
3 & 1.00 & 3.74 & 10 & 1.12 & 0.81 \\
4 & 1.44 & 2.83 & 11 & 0.73 & 0.68 \\
5 & 1.66 & 2.14 & 12 & 0.45 & 0.53 \\
6 & 1.61 & 1.66 & 13 & 0.30 & 0.34 \\
7 & 1.57 & 1.34 & 14 & 0.23 & 0.11 \\
\hline
\end{tabular}

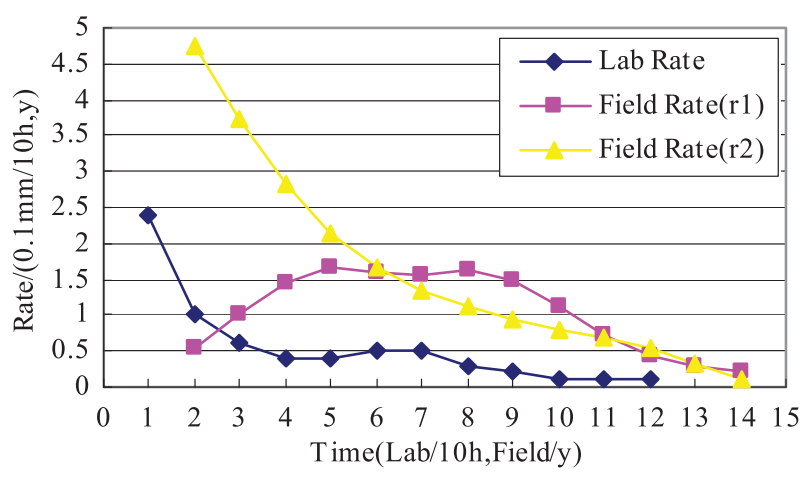

Figure 6. The rate curve of the asphalt ageing.

\section{Conclusions}

(1) The time relationships between the asphalt ageing simulated in the lab and in the field based on the penetration are:

$$
\begin{aligned}
& y_{r_{1}}=-0.00009 x^{3}+0.024 x^{2}-0.0607 x, \\
& y_{r_{2}}=0.0001 x^{3}-0.0068 x^{2}+0.1444 x .
\end{aligned}
$$

In the formula, $y_{r_{1}}$ is fit to the relationship prediction for the early service time of the asphalt pavement ageing in Harbin and $y_{r_{2}}$ is fit to the relationship prediction for the later service time of asphalt pavement ageing.

(2) In the earlier period, the asphalt ageing simulated in the lab is the same with the ageing in the field, but the ageing in the lab becomes faster than the ageing in the field later.

(3) The asphalt ageing rate is the maximum during the first year and becomes slow later. The asphalt pavement ageing will not further happen after 10 years of the service time, which means that the asphalt in the pavement has reached the limit of ageing state. The rate after 2 years is much smaller than the overall average rate. It shows that the asphalt pavement ageing has mainly focused on the earlier period of the service time.

(4) The research has realised the conversion from the asphalt ageing time in the lab to the asphalt ageing time in the field; therefore, it is possible that the data of the asphalt pavement ageing can be obtained rapidly in the lab.

(5) The research has successfully used the BP neural network for the prediction of the asphalt pavement ageing through the ageing data in the lab. The results have proved the feasibility of the programme and can be applied in the recycled asphalt pavement. It has explored 
the way to build the relationships between the asphalt ageing simulated in the lab and in the field.

\section{Acknowledgements}

The authors gratefully appreciate the supports from the province key laboratory of road in Northeast Forestry University.

\section{Disclosure statement}

No potential conflict of interest was reported by the authors.

\section{Funding}

The work received support from the foundations for the project of Heilongjiang Traffic and Transportation Department [No. T1102] and the project of Heilongjiang Academy Department [No. GC12A110].

\section{References}

Austroads. (1997). Asphalt recycling guide. Sydney: Australian Asphalt Pavement Association.

FHWA. (2001). Basic asphalt recycling manual. Washington, DC: Asphalt Recycling and Reclaiming Association.

Gandhia, T., Akisettya, C., \& Amirkhanian, S. (2009). Laboratory evaluation of warm asphalt binder aging characteristics. International Journal of Pavement Engineering, 10(5), 353-359.

Hajja, E. Y., Sebaalya, P. E., \& Shrestha, R. (2009). Laboratory evaluation of mixes containing recycled asphalt pavement (RAP). Road Materials and Pavement Design, 10(3), 495-517.

Hong, F., Guo, R. H., \& Zhou, F. J. (2014). Impact of recycled asphalt pavement material variability on pavement performance. Road Materials and Pavement Design, 15(4), 841-855.

Juristyarinia, P., Davisonb, R., \& Glover, C. J. (2011). Development of an asphalt aging procedure to assess long-term binder performance. Petroleum Science and Technology, 29(21), 2258-2268.

Li, X. J., Zofkaa, A., Marasteanua, M., \& Clyne, T. R. (2006). Evaluation of field aging effects on asphalt binder properties. Road Materials and Pavement Design, 7(1), 57-73.

Ministry of Communication. (2004). Technical specifications for construction of highway asphalt pavements (JTG F40-2004). Beijing: China Communication Press.

Ministry of Communication. (2006). Standard methods of bituminous pavement design for highway engineering (JTG D50-2006). Beijing: China Communication Press.

Ministry of Communication. (2008). Technical specifications for highway asphalt pavement recycling (JTG F41-2008). Beijing: China Communication Press.

Ministry of Communication. (2011). Standard test methods of bitumen and bituminous mixtures for highway engineering (JTG E20-2011). Beijing: China Communication Press.

Parvini, M. (2002). Artificial neural network modeling of pavement performance using expert judgment. Road Materials and Pavement Design, 3(4), 373-384.

Shenoy, A. (2002). A method to estimate the rheological properties of aged asphalt binders without actually aging them. Road Materials and Pavement Design, 3(3), 331-343.

Shi, F. (2010). MATLAB neural network analysis on 30 examples. Beijing: BUAA Press.

Shoenberger, J. E., \& DeMoss, T. A. (2005). Hot-mix recycling of asphalt concrete airfield pavements. International Journal of Pavement Engineering, 6(1), 17-26.

Thomas, K. P. (2002). Impact of water during the laboratory aging of asphalt. Road Materials and Pavement Design, 3(3), 299-315.

Xiao, F. P., Putmana, B. J., \& Amirkhanian, S. N. (2011). Viscosity prediction of CRM binders using artificial neural network approach. International Journal of Pavement Engineering, 12(5), 485-495.

Yuan, Z. R. (1999). The neural network and application. Beijing: Tsinghua University Press.

Zeiada, W. A., Kaloush, K. E., Underwood, B. S., \& Mamlouk, M. E. (2014). Improved method of considering air void and asphalt content changes on long-term performance of asphalt concrete pavements. International Journal of Pavement Engineering, 15(8), 718-730. 